\title{
Survey evidence in China's trademark lawsuits: an empirical study
}

\author{
Qian Zhan* \\ Lecturer, East China Normal University
}

A consumer survey, as an instrument used to gather data on the beliefs and attitudes of consumers towards trademarks or products, is considered to have vital influence in trademark litigation. In recent years, courts have come to rely increasingly on the results of surveys conducted by one or both litigants in trademark lawsuits. The practical issue for trademark litigants is determining whether, when and how to develop survey evidence, given the cost, time, and other constraints. To shed light on this specific issue, we undertook a statistical analysis of trademark infringement cases in China. By examining 17836 cases decided by China's courts over a 16-year period from 2001 through 2016, this article presents an empirical study assessing the statistical relationship between the presentation of survey evidence and case outcomes. The goal of our study is to help trademark litigants to determine the importance and value of presenting consumer surveys in trademark infringement case and make more informed decisions about their litigation strategies.

Keywords: survey evidence, trademark infringement cases, empirical study, China's courts

\section{INTRODUCTION}

The practical issue for trademark litigants is determining whether to develop survey evidence, given the cost, time and other constraints. To shed light on this specific issue, we undertook a statistical analysis of trademark infringement cases in China's courts. By examining 17836 trademark infringement cases over a 16-year period from 2001 through 2016, this article presents an empirical study assessing the statistical relationship between the presentation of survey evidence and case outcomes. The findings presented should assist litigants in making more informed decisions about whether, when and how to present survey evidence.

This article has seven objectives, as follows. First, we assess how often consumer surveys are actually used in China's courts. Second, we contemplate whether submission by a plaintiff or defendant influences the treatment of the survey by the court. Third, we examine the primary evidentiary purpose of surveys prepared by the litigants. Fourth, we discuss the litigants' objections to the surveys submitted by the opposing party. Fifth, we analyse the admissibility of survey evidence and identify the refusal grounds which were mainly invoked by China's courts. Sixth, we discuss the relationship between the presentation of a consumer survey and the courts' finding

* The author gratefully acknowledges the insightful comments from Professor Johanna Gibson and anonymous reviewers of the QMJIP. The author was sponsored by Fundamental Research Funds for the Central Universities (2017ECNU-HWFW032) and the ministeriallevel projects of the China Law Society (CLS2016Y20) while drafting this article. 
of trademark infringement. Lastly, we examine whether the strength of non-survey evidence impacts the power of the survey. From these objectives, we conclude that survey evidence is used infrequently, treated subjectively, and has dispositive power in certain circumstances. Section 2 of this article briefly introduces the definition and value of consumer surveys in trademark lawsuits, highlights the judicial reception given to survey evidence and explores the relevant literature that investigates the presence and influence of surveys. Section 3 introduces our dataset and method of analysis. Section 4 presents the findings of our empirical study and implications for litigants. Section 5 discusses the role of survey evidence in China and briefly presents the limitations of our study. Section 6 concludes.

\section{CONSUMER SURVEYS}

To provide a framework for our empirical research, we begin with a description of a consumer survey. A consumer survey is 'an instrument used to gather data on the beliefs and attitudes of consumers towards trademarks or products' ${ }^{1}$ As a scientific method of data collection, a survey has crucial advantages over less systematic approaches. ${ }^{2}$ Because surveys can offer an 'economical and systematic way to gather information' and draw inferences about a substantial number of individuals, ${ }^{3}$ they are traditionally 'one of the most classic and informative forms of trial evidence'. ${ }^{4}$

\subsection{Survey evidence in trademark lawsuits}

\subsubsection{Value of survey evidence in trademark lawsuits}

A unique facet of trademark law is that 'the critical factual inquiry invariably revolves around consumer perception and reaction' 5 The bulk of trademark disputes requires proving the existence of the likelihood of consumer confusion or the reputation of a trademark. The pivotal legal question in such cases virtually demands showing that the relevant consuming public hold certain perceptions about a mark. For trademark litigants, survey evidence seems to be a natural evidential choice where these issues must be assessed through the eyes of the consuming public. A well-conducted survey can offer strong probative evidence on consumer perception that is hard to duplicate in other ways. ${ }^{6}$ The use of consumer surveys can gather public views without calling multiple witnesses, or seeking any evidence of actual confusion. In exceptional

1. Robert C Bird, 'Streamlining Consumer Survey Analysis: An Examination of the Concept of Universe in Consumer Surveys Offered in Intellectual Property Litigation' (1998) 88 Trademark Rep. 269, 270.

2. Shari Seidman Diamond, 'Reference Guide on Survey Research', in Federal Judicial Center (eds), Reference Manual on Scientific Evidence (Federal Judicial Center, 2nd edn 2000) $359,362$.

3. Shari Seidman Diamond, supra (n 2), at 364.

4. Committee Print to Amend the Federal Trademark Dilution Act: Hearing before the Subcomm on Courts, the Internet, and Intellectual Property of the Comm. on the Judiciary, 108th Cong. 14 (2004) (statement of Robert W Sacoff, Chair, Section of Intellectual Property Law, American Bar Association).

5. Shari Seidman Diamond and David J Franklyn, 'Trademark Surveys: An Undulating Path' (2013-2014) 92 Tex. L. Rev. 2029, 2039.

6. Diamond and Franklyn, supra (n 5), at 2063. 
cases, survey evidence may prove persuasive in the absence of other positive evidence. It may be useful to fill an evidentiary gap where a survey is the only possible form of evidence that will clarify the perceptions of a cross-section of the purchasing public. ${ }^{7}$

The value of a consumer survey in trademark litigation is that it 'scientifically approximates the mental associations of prospective consumers' with the goal of clarifying how the target population will perceive the specific trademarks. ${ }^{8}$ Information is preferable to intuition. For courts, a consumer survey is 'an effective and accurate way' to ensure that trademark cases are decided based on empirical facts, instead of on judicial determination based on a judge's own perception of the prospective purchaser's attitude towards a particular mark. ${ }^{9}$ A consumer survey, if properly designed, can correct judicial misimpressions. The scientific character of a consumer survey process lends it more reliability when compared to a direct determination of the judge, which tends to be subjective and based heavily on impressions or personal biases.

\subsubsection{Judicial reception of survey evidence in key jurisdictions}

In recent years, courts have come to rely increasingly on the results of surveys conducted by one or both litigants in trademark lawsuits. However, the attitude towards surveys in trademark proceedings varies from jurisdiction to jurisdiction. Courts around the world have varying rules on using consumer surveys as evidence. Typically, in the United States, courts have long accepted survey evidence on a variety of issues. Some courts have described consumer surveys as 'the most direct and persuasive evidence' to establish trademark infringement. ${ }^{10}$ In terms of proving secondary meaning or genericide, consumer surveys are 'virtually indispensable'. ${ }^{11}$ Some courts have on occasion even faulted litigants for not bringing a survey. ${ }^{12}$ Likewise, survey evidence is frequently presented in trademark proceedings and principally admitted in German courts as evidence. ${ }^{13}$ Survey evidence was first introduced into a court in the year $1941 .{ }^{14}$ The use of surveys generally falls into two evidential categories: evidence of likelihood of confusion and evidence of reputation of a trademark. The German courts in principal accept surveys submitted by the parties and regard them as useful and important sources of evidence. ${ }^{15}$

7. Hans Zeisel, 'Uniqueness of Survey Evidence' (1960) 45 Cornell L. Rev. 322, 323.

8. Michael Rappeport, 'Litigation Surveys - Social "Science" as Evidence' (2002) 92 Trademark Rep. 957, 959.

9. Diamond and Franklyn, supra (n 5), at 2029.

10. Checkpoint Sys., Inc. v Check Point Software Techs., Inc., 269 F.3d 270, 283 n.10 (3d Cir. 2001); Vision Sports, Inc. v. Melville Corp., 888 F.2d 609, 615 (9th Cir. 1989); McNeil Nutritionals, L.L.C. v. Heartland Sweeteners L.L.C., 566 F. Supp. 2d 378, 392 (E.D. Pa. 2008). 11. Co-Rect Prods. Inc. v Marvy! Adver. Photography, Inc., 780 F.2d 1324, 1333 n.9 (8th Cir. 1985).

12. E.S. Originals Inc. v Stride Rite Corp., 656 F. Supp. 484, 490 (S.D.N.Y. 1987); Ortho Pharm. Corp. v. Cosprophar, Inc., 32 F.3d 690, 695 (2d Cir. 1994); Citigroup v City Holding Co., 2003 U.S. Dist. LEXIS 1845 (S.D.N.Y. Feb. 10, 2003); Medici Classics Productions LLC v Medici Group LLC, 590 F. Supp. 2d 548, 556 (S.D.N.Y. 2008); Citigroup v City Holding Co., 2003 U.S. Dist. LEXIS 1845 (S.D.N.Y. Feb. 10, 2003).

13. Kate Swaine, Alexander Bayer, Julia Holden and Lisa Lennon 'The Value and Treatment of Survey Evidence in Different Jurisdictions' (2010) 100 Trademark Rep. $1373-405$, at $1386-7$.

14. RG, 'Alpenmilch', 1941 GRUR, 328, 330.

15. Swaine et al., supra (n 13), at 1394. 
By contrast, the United Kingdom takes a different stance on the issues of survey evidence. The English judiciary has always treated survey evidence in trademark lawsuits with a high degree of caution. Survey evidence has been criticized in a series of trademark cases. ${ }^{16}$ The weight of survey evidence relies on the methodology of the survey. Judge Whitford laid out the Raffles criteria that survey evidence should meet if it is to have validity. ${ }^{17}$ However, the value of survey evidence has remained much maligned by the judiciary. Survey evidence may be admitted only with the approval and guidance of the court. It has been made clear that such permission will only be granted if (a) survey evidence is likely to be of real value, (b) the Raffles guidelines will be followed and (c) that the value justifies the cost. ${ }^{18}$ Justice Lewison ruled that these criteria are likely to be satisfied only in a special or unusual case, and using survey evidence to demonstrate the view of the public 'is generally of little or no value'.

The same criticisms are frequently voiced against survey evidence in Australia. Australian courts have been profoundly sceptical about surveys, and have been slow to recognize surveys as an acceptable form of evidence. Historically surveys were viewed as mere hearsay prior to $1990 .{ }^{19}$ Since the judicial shift with regard to survey evidence as admissible in Arotts, survey evidence has been infrequently used in trademark cases. ${ }^{20}$ Although the Australia court has issued a Practice Note to assist in ensuring the admissibility of surveys, it concerns the procedure only and does not contain detailed guidelines regarding survey methodology. Survey evidence is often accorded limited weight as the methodologies of the surveys are routinely criticized by the court. ${ }^{21}$ In short, the Australian courts do not view survey evidence favourably and the success rate of surveys remains appallingly low.

\subsection{Relevant literature on survey evidence}

\subsubsection{Case studies on survey evidence}

Scholars have explored consumer surveys from a variety of perspectives. ${ }^{22}$ Casebased studies have examined the role of consumer surveys in a majority of trademark contexts. While most of these studies examined the effects of the survey method on the likelihood of estimating confusion, ${ }^{23}$ several articles discussed surveying secondary

16. O2 Ltd v Hutchinson $3 G$ Ltd [2006] EWHC 601; UK Channel Management Ltd v E! Entertainment Television Inc [2008] F.S.R. 5; The esure Insurance Ltd v Direct Line Insurance plc [2008] EWCA Civ 842.

17. Imperial Group plc \& Another v Philip Morris Limited \& Another [1984] R.P.C. 293.

18. Interflora $v$ Marks and Spencer [2012] EWCA Civ 1501.

19. Arnotts Ltd v Trade Practices Commission [1990] 24 FCR 313.

20. Cadbury Schweppes Pty Ltd v Effem Foods Pty Ltd [2005] 66 IPR 387; Domino's Pizza Inc and Another v Eagle Boys Dial-A-Pizza Australia Pty Ltd [1995] 31 IPR 592.

21. Vicki Huang, Kimberlee Weatherall and Elizabeth Webster, 'The Use of Survey Evidence in Australian Trade Mark and Passing Off Cases' [2011] <http://dro.deakin.edu.au/view/ DU:30045831> accessed 24 February 2017.

22. Lawrence E Evans, Jr and David M Gunn, 'Trademark Surveys' (1989) 79 Trademark Rep. 1; Peter Weiss, 'The Use of Survey Evidence in Trademark Litigation: Science, Art or Confidence Game?' (1990) 80 Trademark Rep. 71; Michael Rappeport, 'Litigation Surveys: Social Science as Evidence' (2002) 92 Trademark Rep. 957, 971.

23. Itamar Simonson, 'The Effect of Survey Method on Likelihood of Confusion Estimates: Conceptual Analysis and Empirical Test' (1993) 83 Trademark Rep. 364; JB Swann, 'Likelihood of Confusion Studies and the Straightened Scope of Squirt' (2008) 98 Trademark Rep. 739, 746; 
meaning. ${ }^{24}$ Scholars have also reviewed cases to evaluate what evidence courts consider in making findings of genericide or trademark dilution. ${ }^{25}$ In addition, some articles discuss the reception of survey evidence in deceptive advertising cases. ${ }^{26}$

The development of standards for survey evidence is also an important focus in the legal literature. ${ }^{27}$ Legal treatises present elaborate guidelines for assessing a survey's effectiveness. ${ }^{28}$ Guidelines exist on universe definition, ${ }^{29}$ sampling method, ${ }^{30}$ questionnaire phrasing and format, ${ }^{31}$ qualifications of the surveyor, implementation of an investigation, ${ }^{32}$ data collection and survey reports. There are also some contributions to comparative studies on the treatment of survey evidence of different jurisdictions. ${ }^{33}$

R Bradlee Boal, 'Techniques for Ascertaining Likelihood of Confusion and the Meaning of Advertising Communications' (1983) 73 Trademark Rep. 405, 413; John P Liefeld, 'How Surveys Overestimate the Likelihood of Consumer Confusion' (2003) 93 Trademark Rep. 939, 941. 24. Vincent N Palladino, 'Surveying Secondary Meaning' (1994) 84 Trademark Rep. 155 (1994); Vincent N Palladino, 'Techniques for Ascertaining If There Is Secondary Meaning' (1983) 73 Trademark Rep. 391 1983; David HB Bednall, Phillip Gendall, Janet Hoek and Stephen Downes, 'Color, Champagne, and Trademark Secondary Meaning: Devilish Detail' (2012) 102 Trademark Rep. 967.

25. E Deborah Jay, 'Genericness Survey in Trademark Disputes: Evolution of Species' (2009) 99 Trademark Rep. 1118; Ralph H Folsom and Larry L Teply, 'Surveying "Genericness" in Trademark Litigation' (1988) 78 Trademark Rep. 1 (1988 ); Jerre B Swann and Vincent N Palladino, 'Surveying "Genericness": A Critique of Folsom and Teply' (1988) 78 Trademark Rep. 179; Allan W Leiser and Carl R Schwartz, 'Techniques for Ascertaining Whether a Term is Generic' (1983) 73 Trademark Rep. 376.

26. Jacob Jacoby, Amy H Handlin and Alex Simonson, 'Survey Evidence in Deceptive Advertising Cases under Lanham Act: Review of Comments from the Bench' (1994) 84 Trademark Rep. 541; E Deborah Jay, 'Ten Truths of False Advertising Surveys' (2013) 103 Trademark Rep. 1113.

27. Shari Seidman Diamond, supra (n 2); Larry C Jones, 'Developing and Using Survey Evidence in Trademark Litigation' (1989) 19 Memphis St. U. L. Rev. 471; Robert C Sorensen, 'Survey Research Execution in Trademark Litigation: Does Practice Make Perfection?' (1983) 73 Trademark Rep. 349; Fred W Morgan, 'Judicial Standards for Survey Research: An Update and Guidelines' (1990) 54 J. Marketing 59.

28. Susan J Becker, 'Public Opinion Polls and Surveys as Evidence: Suggestions for Resolving Confusing and Conflicting Standards Governing Weight and Admissibility' (1991) 70 Or. L. Rev. 463.

29. Robert C Bird, 'Streamlining Consumer Survey Analysis: An Examination of the Concept of Universe in Consumer Surveys Offered in Intellectual Property Litigation' (1998) 88 Trademark Rep. 269; Shashank Upadhye, 'Trademark Surveys: Identifying the Relevant Universe of Confused Consumers' (1997-1998) 8 Fordham Intell. Prop. Media \& Ent. L.J. 549. 30. Jacob Jacoby and Amy H Handlin, 'Non-probability Sampling Designs for Litigation Surveys' (1991) 81 Trademark Rep. 169; John Paul Reiner, 'The Universe and Sample: How Good Is Good Enough?' (1983) 73 Trademark Rep. 366.

31. Floyd J Fowler, Jr, 'How Unclear Terms Affect Survey Data' (1992) 56 Pub. Op. Q. 219; Howard Schuman, 'Ordinary Questions, Survey Questions, and Policy Questions' (1986) 50 Pub. Opinion Q. 432. Jon A Krosnick et al., 'The Impact of "No Opinion" Response Options on Data Quality: Non-Attitude Reduction or Invitation to Satisfice?' (2002) 66 Pub. Op. Q. 371. 32. JB Swann, "A "Reading" Test or a "Memory" Test: Which Survey Methodology is Correct?' (2005) 95 Trademark Reporter 876; Hal Poret, 'A Comparative Empirical Analysis of Online Versus Mall and Phone Methodologies for Trademark Surveys' (2010) 100 Trademark Rep. 756; G Gelb and B Gelb, 'Internet Surveys for Trademark Litigation: Ready or Not, Here They Come' (2007) 97 Trademark Rep. 1073.

33. Ruth M Corbin and A Kelly Gill, Survey Evidence and the Law Worldwide (LexisNexis: 2008); Swaine et al., supra (n 13). 


\subsubsection{Empirical studies on surveys evidence}

In spite of hundreds of articles that concern consumer surveys, very little empirical evidence exists to show how consumer surveys are actually used in trademark lawsuits.

While case-based analysis is of great importance, empirical studies that examine a substantial dataset of trademark case law are most relevant to our research. There has been some research into the effectiveness of surveys in trademark cases in the United States, the European Union and Australia. ${ }^{34}$

For example, Morgan reviewed all federal and state cases from 1900 to 1989 and concluded that over time the US courts have increasingly accepted surveys into evidence. ${ }^{35}$ By contrast, Jacoby and Morrin reviewed federal cases from 1994 through 1997 and concluded that courts often heavily discount survey evidence in trademark infringement cases. ${ }^{36}$ Similarly, Austin conducted an impressionistic survey of trademark infringement from 1993 to 2003, which discloses that in about half the litigated cases, litigants offered no survey evidence to the court or, if they did, courts accorded it little weight. ${ }^{37}$ The author concluded that a significant portion of trademark jurisprudence is developed without the aid of empirical evidence about potential consumer reactions. Unfortunately, those prior studies never examined the relationship between survey evidence and case outcomes.

Beebe identified 331 trademark cases between 2000 and 2004 and concluded that the conventional view of the utility of survey evidence may be incorrect and survey evidence played a relatively minor role in the trial context. ${ }^{38}$ However, Beebe's analysis only briefly addressed survey data and did not indicate how often surveys were introduced. A subsequent study conducted by Blum and Fox looked at 224 cases from the Southern District of New York, from 1994 through 2008, and found that surveys were less frequently employed by litigants and credited by the courts. ${ }^{39}$ In contrast with Beebe's results, their findings suggested a stronger relationship between credited survey evidence and the case outcomes. ${ }^{40}$ Although these studies analysed the impact of judges' crediting survey evidence, they did not analyse the judges' decisionmaking process in deciding why survey evidence favoured the litigants.

Sarel and Marmorstein examined the relationship between the use of survey evidence by trademark plaintiffs and injunction outcomes in 126 trademark infringement cases decided by US District Courts between 2001 and 2006. ${ }^{41}$ Their study showed that plaintiffs received a modest improvement in outcomes through the presentation

34. Anne Niedermann, 'Surveys as Evidence in Proceedings before OHIM' (2006) 37 IIC 260. See also Vicky Huang, supra (n 21).

35. Fred W Morgan, 'Judicial Standards for Survey Research: An Update and Guidelines' (1990) 54 J. Marketing 59, 64.

36. Jacob Jacoby and Maureen Morrin, “Not Manufactured or Authorized by ...": Recent Federal Cases Involving Trademark Disclaimers' (1998) 17 J. Pub. Pol'y \& Marketing 97.

37. Graeme W Austin, 'Trademarks and the Burdened Imagination' (2004) 69 Brook. L. Rev. 827.

38. Barton Beebe, 'An Empirical Study of the Multifactor Tests for Trademark Infringement' (2006) 94 Cal. L. Rev. 1581, 1642.

39. Kevin Blum, Ariel Fox, et al., 'Consistency of Confusion? A Fifteen-Year Revisiting of Barton Beebe's Empirical Analysis of Multifactor Tests for Trademark Infringement' (2010) Stan. Tech. L. Rev. 3.

40. Kevin Blum, Ariel Fox, et al., ibid, at 30 .

41. Dan Sarel and Howard Marmorstein, 'The Effect of Consumer Surveys and Actual Confusion Evidence in Trademark Litigation: An Empirical Assessment' (2009) 99 Trademark Rep. 1416. 
of survey evidence. ${ }^{42}$ The quality of surveys presented is strongly associated with case outcomes. ${ }^{43}$ The author also concluded that use of consumer surveys resulted in a statistically significant increase in the likelihood of obtaining an injunction at each level of name or product similarity. ${ }^{44}$ The limitation of this study is that it did not take the defendant's survey into account and only focused on the grant of injunctions.

Of greatest relevance to our research is a comprehensive study by Bird and Steckel. ${ }^{45}$ They present an empirical study investigating the role of consumer surveys in federal courts by examining 553 opinions between 2000 and 2006. They used a series of logistic regressions to investigate the impact of a consumer survey on the outcome of court cases. First, they found that survey evidence is used infrequently in trademark infringement litigation. ${ }^{46}$ Second, they found that surveys are not universally influential. While a plaintiff's submission of a survey does not have a significant relationship on a finding of confusion, a defendant's submission negatively correlated with a finding of a likelihood of confusion. ${ }^{47}$ Moreover, the impact of a credited survey differs according to which litigant submitted the survey. ${ }^{48}$ The author concluded that the courts treat plaintiff-produced surveys and defendant-produced surveys differently. Third, they pointed out that survey evidence has the potential to be either dispositive or useless depending on the context of the non-survey evidence. ${ }^{49}$ As Bird and Steckel recognized, their study did not measure the role of surveys in cases that settled. The most recent empirical study of survey evidence was conducted by Diamond and Franklyn, which is the first attempt to measure the use of survey evidence in the pre-litigation context. ${ }^{50}$ Their study offers an explanation of why surveys may be underrepresented in reported cases, and their results indicate that surveys are used heavily in pre-trial assessments and strategic decision making. ${ }^{51}$

Based on the literature review, the role and effect of surveys in China's courts seem to be inconclusive. The literature suffers from a lack of an empirical understanding of how survey evidence is actually treated in China's courts. Addressing this issue has great practical implications for foreign enterprises faced with trademark disputes in China. For our work on consumer surveys, the relevant question is what impact survey evidence has on the outcome of trademark infringement cases in China's courts. Our research builds on the aforementioned works on consumer surveys and offers an empirical understanding about how courts in China actually treat survey evidence in trademark lawsuits.

\section{METHODOLOGY AND CRITERIA}

The practical issue for trademark litigants is to determine whether to develop survey evidence. To shed light on this issue, we undertook a statistical analysis of trademark infringement cases in China's courts.

42. Ibid, at 1430 .

43. Ibid, at 1431 .

44. Ibid, at 1427.

45. Robert C Bird and Joel H Steckel, 'The Role of Consumer Surveys in Trademark Infringement: Empirical Evidence from the Federal Courts' (2012) 14(4) University Pennsylvania Journal of Business Law 1013-53.

46. Ibid, at 1017.

47. Ibid, at 1017.

48. Ibid, at 1037.

49. Ibid, at 1041.

50. Diamond and Franklyn, supra (n 5).

51. Ibid, at 2061. 


\subsection{Data collection}

For our work on consumer surveys, the relevant question is what impact surveys have on the outcome of court cases. The study methods and presentation of the data follow.

\subsubsection{Defined population}

We obtained data by gathering judicial opinions using PkuLaw, a professional legal research database. The population for this study was defined as all trademark infringement cases which were litigated and decided between 2001 and 2016 in China's courts. A case had to be tried and resolved during this 16-year period to be included in the study. The dataset did not include cases that focused primarily on other legal issues, to avoid redundancy. Therefore we removed from the dataset any unfair competition cases, or domain name cases that might skew the results. Based on the above criteria, the dataset consisted of 17836 cases.

\subsubsection{Coding variables}

The researchers classified and coded the cases using a predetermined set of variables that we considered relevant. The variables introduced in this study are divided into two groups: classification variables and outcome variables. Each case was read and coded carefully by two trained researchers so as to ensure accuracy.

The classification variables included: (a) according to which party submitted a survey: 'Plaintiff-submitted' survey, 'Defendant-submitted' survey, 'Both-submitted' survey and 'Court-commissioned' survey; (b) according to the evidentiary purpose of a survey: 'Confusion' survey, 'Reputation' survey and 'Both' survey; (c) according to whether the litigants raised an objection to the survey evidence submitted by the opposing party: 'Objected' survey and 'Accepted' survey; (d) the similarity of the parties' marks, which we refer to as 'Name similarity' and the relatedness of the parties' respective goods or services, which we refer to as 'Product similarity'.

The outcome variables included: (a) 'Rejected' survey - the survey was entirely rejected by the court - and 'Admitted' survey - the survey was admitted into evidence by the court. It should be noted that the 'Rejected' category refers only to cases in which surveys were completely rejected, not those cases where the weight of surveys was reduced (and thereby included in the 'Admitted' category); (b) 'Infringement' - the court finally found the defendant infringed the trademark rights of the plaintiff - and 'Non-infringement' - The court failed to find trademark infringement.

\subsection{Plan of analysis}

We performed our analysis in the following multiple stages.

\subsubsection{Stage 1}

We begin our study by asking the basic question of how often litigants submitted consumer surveys as supporting evidence in trademark infringement cases. In order to answer this question, we simply counted the number of surveys that were submitted relative to the number of total cases in our dataset. We screened all the cases 
concerning consumer survey evidence, by using the following search terms: 'survey evidence', 'consumer survey' and 'survey report'. When a court did not discuss survey evidence it was deemed 'irrelevant'. This frequency can imply some information about the influence of survey evidence over trademark disputes.

\subsubsection{Stage 2}

In addition to counting survey use, we classified our surveys according to which litigant submitted survey evidence to the court. This variable segments the data according to whether a plaintiff or defendant submitted the evidence. In rare cases, both plaintiffs and defendants submitted a survey in the same case, and we coded such instances accordingly. It is worth noting that in certain cases the survey evidence was commissioned by the courts. We separated plaintiff from defendant because the parties may have different motivations in the production of survey evidence in trademark disputes. The plaintiff bears the burden of proof and would be more motivated to produce survey evidence. The defendant must merely show that the plaintiff's evidence was insufficient. Thus, the defendant may be less motivated to submit a survey. Therefore, the quantity and impact of survey production might differ between the plaintiff and the defendant.

\subsubsection{Stage 3}

The third stage focuses on what issues the litigant wants to prove by submitting a survey. This variable segments the data according to whether the litigants prove the likelihood of confusion between contesting marks, or the reputation of the disputed mark. In some cases, the litigant managed to address both issues, and we code such instances accordingly. As plaintiffs and defendants have different evidentiary purposes in trademark cases, we test the impact of plaintiff-submitted surveys and defendant-submitted surveys as classification variables.

\subsubsection{Stage 4}

In Stage 4, we sorted our surveys according to whether the litigant raised an objection to the survey evidence submitted by the other party. This variable segments the data according to whether the litigants oppose or accept survey evidence. As plaintiffs and defendants have different attitudes towards survey evidence submitted by the contesting party, we tested the impact of plaintiff-submitted surveys and defendantsubmitted surveys as classification variables.

\subsubsection{Stage 5}

The fifth stage of our analysis produces insight into the admissibility of survey evidence. Our dataset reports whether a submitted survey was credited by the court. Not all surveys are treated equally: some courts reject survey evidence as lacking scientific rigour; other courts are more receptive. We account for this differential treatment by evaluating whether a survey was 'admitted' or 'rejected' by a court, and list the refusal grounds that the courts mainly invoked to reject a survey as evidence. We developed our analysis through the estimation of three models, each of which tests the impact of different classification variables on the court's treatment of survey evidence. 


\subsubsection{Stage 6}

The sixth stage of our analysis, the most important one, places emphasis on the effectiveness of survey evidence. We sorted the surveys according to whether the court finally found trademark infringement or not. This variable segments the data according to whether the plaintiff or defendant won the case. We developed our analysis through the estimation of three models, with each model testing the impact of different variables on the court's finding of trademark infringement.

\subsubsection{Stage 7}

In the previous stages, we discerned whether the presence of a survey, the author of a survey, the evidentiary purpose of a survey and the litigant's objection to a survey, had a significant impact on the admissibility of a survey and the trademark infringement finding. These stages are incomplete since the possibility exists that non-survey factors may overwhelm the survey evidence and render it immaterial. The impact of survey evidence might be influenced by the strength of non-survey evidence in the case.

We address this problem by examining whether survey evidence still holds influence when taking into account the impact of non-survey factors on judicial outcomes. We limited our consideration to only two factors that all courts rely upon when determining trademark infringement: the similarity of the parties' trademarks (name similarity), and the proximity of litigants' goods and services (product similarity). We selected these factors for two reasons. First, China's courts uniformly consider these two factors as the most important components in trademark infringement cases across the country. Second, these two similarity factors could be assessed in a more objective and reliable way than other variables. ${ }^{52}$ We incorporated these classification variables into the analysis to show the impact of non-survey proof on consumer survey evidence.

\section{STUDY FINDINGS}

In this section, we report the results of our analyses. We also discuss how our findings contribute to our understanding of survey evidence and its influence in China's trademark litigation. While some results are as we would expect, others are unexpected and surprisingly illuminating in terms of perceptions about consumer surveys.

\subsection{Finding 1: frequency of use of survey evidence}

Figure 1 tracks the use of surveys between 2001 and 2016 in specific numerical terms by year: survey evidence was used relatively often in the years 2005 (16), 2006 (19), 2007 (11), 2008 (11) and 2011 (11), and rarely used in other years. Our data show that survey use is not widespread in trademark infringement litigation. Out of the 17836 cases reviewed for our dataset, only 90 involved the presentation of survey evidence ( 0.5 per cent). As noted earlier, our results on the use of surveys differed dramatically from those in other jurisdictions observed by commentators.

We found no evidence that surveys are used by a majority of litigants to prove trademark infringement in China's courts. The apparent implication is that consumer

52. Sarel and Marmorstein, supra (n 41), at 1423-4. 


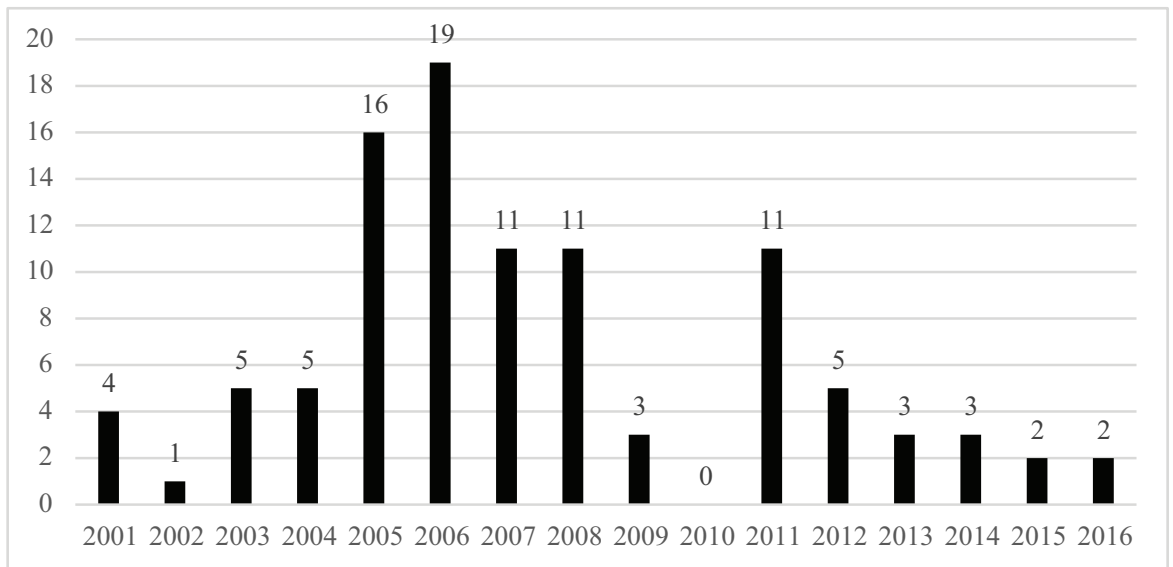

Figure 1 Use of survey evidence in trademark infringement cases

surveys are neither omnipresent nor important in trademark infringement cases. Many factors may account for the low use of survey evidence in China's courts.

The primary driving force affecting survey use is cost. A properly conducted survey is a complex, time-consuming and expensive process, which may deter litigants from preparing a survey. Smaller firms, in particular, may not be able to afford to create this kind of evidence. The second prominent factor was other evidence available in the case. Survey evidence is one of multiple factors that the court would consider. It is not per se dispositive. The legal and factual nature of the case may make survey evidence irrelevant. For example, with good evidence of actual confusion or nearly identical marks, a survey may be unnecessary or redundant. ${ }^{53}$ Survey evidence is most likely to be submitted when other forms of evidence in the case are equivocal or absent. This might clarify why a survey is not prepared, even when cost is not a key issue. A third factor was the value of the mark at issue: when the potential loss would be very harmful, the cost of obtaining survey evidence is worth assuming. The fourth factor was the likelihood that the survey results would favour or disfavour the litigant. No litigants would submit a survey which produced unfavourable results for their claim.

We may be underestimating the use of surveys in trademark litigation since the data we analyse exclude those cases in which surveys were never introduced in a court's judicial decisions. ${ }^{54}$ Earlier studies found ample evidence to suggest that surveys enjoy a substantial life before trial as critical evaluative and leveraging tools. ${ }^{55}$ A real possibility exists that consumer surveys may have an indirect effect on trademark infringement cases even if they do not appear in judicial opinions. As noted by Bird and Diamond, what we observe in the court may merely be the 'tip of the iceberg' of survey usage in trademark disputes. Therefore, even though our results show that survey evidence is not present in the majority of trademark infringement cases, one should take care not to ignore the importance of survey evidence entirely.

53. Diamond and Franklyn, supra (n 5), at 2048.

54. Bird and Steckel, supra (n 45), at 1036.

55. Diamond and Franklyn, supra (n 5), at 3050. 
Table 1 Author of survey evidence

\begin{tabular}{lcc}
\hline & Case number & Survey number \\
\hline Plaintiff-submitted & $56(62.2 \%)$ & $59(63.4 \%)$ \\
Defendant-submitted & $20(22.2 \%)$ & $23(24.7 \%)$ \\
Both-submitted & $3(3.3 \%)$ & \\
Court-commissioned & $11(12.2 \%)$ & $11(11.8 \%)$ \\
Total & $90(100 \%)$ & $93(100 \%)$ \\
\hline
\end{tabular}

\subsection{Finding 2: author of survey evidence}

The results reported in Table 1 shows which party prefers to present consumer surveys in trademark infringement cases. Surveys can be commissioned by the court or by the parties. The variable was defined at four levels: 'Plaintiff-submitted' - the survey was submitted by the plaintiff; 'Defendant-submitted'- the survey was produced by the defendant; 'Both-submitted' - the survey was presented by both parties and 'Courtcommissioned': the survey was conducted under the court's authorization.

The plaintiffs submitted a survey in 56 out of 90 cases (62.2 per cent), defendants in 20 (22.2 per cent), and in three cases both plaintiffs and defendants submitted a survey. It should be noted that in 11 cases the court commissioned a professional survey company to submit a survey. In aggregate, there are 93 survey reports in 90 cases, out of which the plaintiff submitted 59 surveys (63.4 per cent), the defendant submitted 23 surveys ( 24.7 per cent), and the court commissioned 11 surveys (11.8 per cent). The data in Table 1 indicates that a majority of the surveys were conducted on behalf of plaintiffs. A variety of reasons may explain this phenomenon. The plaintiff typically bears more burden to prove the likelihood of confusion between contesting marks, or the reputation of the senior mark. Thus, plaintiffs will be more motivated to produce such evidence. By contrast, because defendants need only to counter the plaintiffs' evidence in order to win, they present fewer surveys than plaintiffs. ${ }^{56}$ Considering the time and money involved in conducting a survey, the defendant may be less motivated to submit a survey.

\subsection{Finding 3: evidentiary purpose of survey evidence}

The data in Table 2 indicates what legal issue a survey was designed to address. The use of surveys in China falls into two evidential categories: evidence of likelihood of confusion; and evidence of reputation of a trademark. Consequently, the variable was defined at three levels: 'Confusion' - the survey was designed to prove the existence or non-existence of likelihood of consumer confusion; ${ }^{57}$ 'Reputation' - the survey was

56. Bird and Steckel, supra (n 45), at 1037.

57. See Article 57 of China Trademark Law, as amended in August 30, 2013: 'Any of the following acts shall constitute an infringement on the exclusive rights to the use of a registered trademark: (1) Using a trademark that is identical with a registered trademark on the same kind of goods without obtaining licensing from the registrant of the registered trademark; (2) Using a trademark that is similar to a registered trademark on the same kind of goods, or using a trademark that is identical with or similar to the registered trademark on similar goods without obtaining licensing from the registrant of the registered trademark, and is likely to cause confusion, shall constitute an infringement on the exclusive rights to the use of a registered trademark'. 
Table 2 Evidentiary purpose of survey evidence

\begin{tabular}{lcccc}
\hline & Confusion & Reputation & Both & Total \\
\hline Plaintiff-submitted & $10(16.9 \%)$ & $39(66.2 \%)$ & $10(16.9 \%)$ & $59(100 \%)$ \\
Defendant-submitted & $14(60.9 \%)$ & $5(21.7 \%)$ & $4(17.4 \%)$ & $23(100 \%)$ \\
Court-commissioned & $0(0 \%)$ & $11(100 \%)$ & $0(0 \%)$ & $11(100 \%)$ \\
Total & $24(25.8 \%)$ & $55(59.1 \%)$ & $14(15.1 \%)$ & $93(100 \%)$ \\
\hline
\end{tabular}

produced to prove whether a mark was a well-known mark; ${ }^{58}$ and 'Both' - the survey was conducted to address both issues.

As Table 2 indicates, the topic most commonly addressed in a survey was the reputation of a disputed mark. Out of 93 surveys, 55 surveys (59.1 per cent) were used to measure trademark reputation, 24 surveys ( 25.8 per cent) were used to prove the likelihood of confusion and 14 surveys (15.1 per cent) were used for both purposes. Our results in Table 2 show that litigants may have different evidentiary purposes in submitting a consumer survey. The plaintiffs are more inclined to prove the reputation of their mark. Out of 59 surveys submitted by the plaintiff, 39 surveys ( 66.2 per cent) were designed to prove the senior mark has acquired enough brand awareness to be a well-known mark, 10 surveys (16.9 per cent) were designed to prove the existence of confusion, and 10 surveys (16.9 per cent) had a dual purpose. By contrast, the defendants were more willing to prove the non-existence of likelihood of confusion between disputed marks. Out of 23 surveys submitted by the defendant, 14 surveys (60.9 per cent) were produced to prove the non-existence of confusion between contesting marks, only five surveys (21.7 per cent) were produced to prove the reputation of the junior mark, and four surveys (17.4 per cent) had multiple purposes. Strikingly, the courts pay close attention to the survey's value in proving the relevant consumers' recognition of the senior mark. It is noteworthy that all 11 surveys (100 per cent) that the court commissioned a survey company to produce were conducted to prove the reputation of the senior mark. So far, no survey ( 0 per cent) that was ordered by the courts in China was intended to prove the likelihood of confusion in trademark infringement cases.

\subsection{Finding 4: litigants' objection to survey evidence}

The data in Table 3 analyse whether the contesting parties oppose or accept the surveys submitted by the other party in trademark infringement cases. The variable was defined at two levels: 'Objected' - the survey was challenged by the litigants; and 'Accepted' - the survey was accepted as evidence by both litigants.

Consumer surveys in court undergo an aggressive examination for methodological flaws by the opposing party, with criticisms related to virtually every aspect of a survey's design. Out of 93 surveys, 42 surveys ( 45.2 per cent) were challenged by either party, and 51 surveys (54.8 per cent) were accepted by both parties.

Our results in Table 3 show that litigants may have dramatically different attitudes towards the survey evidence submitted by the opposing party. The plaintiffs are inclined

58. See Article 2 of Provisions of July 3, 2014, on the Recognition and Protection of Wellknown Trademarks (promulgated by Order No. 66 of the State Administration for Industry and Commerce): "The term "well-known trademarks" refers to trademarks that are well known by the relevant public in China'. 
Table 3 Litigant's objection to survey evidence

\begin{tabular}{lccc}
\hline & Objected & Accepted & Total \\
\hline Plaintiff-submitted & $31(52.5 \%)$ & $28(47.5 \%)$ & 59 \\
Defendant-submitted & $16(69.6 \%)$ & $7(30.4 \%)$ & 23 \\
Court-commissioned & $1(9 \%)$ & $10(91 \%)$ & 11 \\
Total & $42(45.2 \%)$ & $51(54.8 \%)$ & 93 \\
\hline
\end{tabular}

to raise an objection to the surveys produced by the defendant. Out of 23 surveys submitted by the defendant, 16 surveys ( 69.6 per cent) were challenged by the plaintiff, and only seven surveys (30.4 per cent) were accepted by the plaintiff. Simply put, more than two-thirds of the defendant-submitted surveys were criticized by the plaintiffs on the grounds of failing to conform to methodological standards.

The results are significantly lower than for the 'Plaintiff-submitted' category. Out of 59 surveys submitted by the plaintiff, 31 surveys ( 52.5 per cent) were challenged by the defendant, and 28 surveys ( 47.5 per cent) were accepted by the defendant. Only half of these plaintiff-submitted surveys were criticized by the defendants for methodological deficiencies. The data implies, in part, that the plaintiffs are pickier about the survey evidence than the defendants in trademark litigation. This conclusion is somewhat unexpected since the main burden of proof for defendants is to criticize the evidence submitted by the plaintiffs in order to win the case.

Unsurprisingly, the surveys commissioned by the court seemed to have greater persuasive power and were accepted by both parties in most cases. It is worthwhile noting that among 11 surveys commissioned by the court. Only one survey ( 9 per cent) was objected to by the defendant. The other 10 surveys (91 per cent) were universally accepted by both plaintiffs and defendants. Therefore, if the litigants consider using a consumer survey as supporting evidence, it might be a wise move to apply to the courts to commission a survey conducted by a neutral survey company, instead of preparing a survey themselves.

\subsection{Finding 5: admissibility of survey evidence}

In this section, the association between the presentation of survey evidence and whether the court credited survey evidence is reported. The outcome variable was defined at two levels: 'Rejected' - the survey was presented and entirely rejected by the court; and 'Admitted' - the survey was presented and admitted into evidence. We considered a survey to be admitted if the judge indicated that, despite any flaws, the survey contained at least some probative value in favour of the party submitting the survey. As our results revealed, out of 93 surveys, the court admitted 68 surveys (75.3 per cent) as evidence and rejected only 25 surveys ( 24.75 per cent). Surprisingly, China's courts have accepted three-quarters of the surveys as evidence, which is a rare phenomenon compared to other jurisdictions.

Just because a survey is presented in court does not mean that the court will consider it admissible. The admissibility and weight of survey evidence is most likely to be influenced by the methodology of conducting a survey. In 25 rejected surveys, the courts raised legitimate concerns over both the validity and reliability of survey evidence introduced by the litigants. Criticisms related to virtually every aspect of a survey's methodology, often giving judges reasons to discount surveys before them. As indicated in 


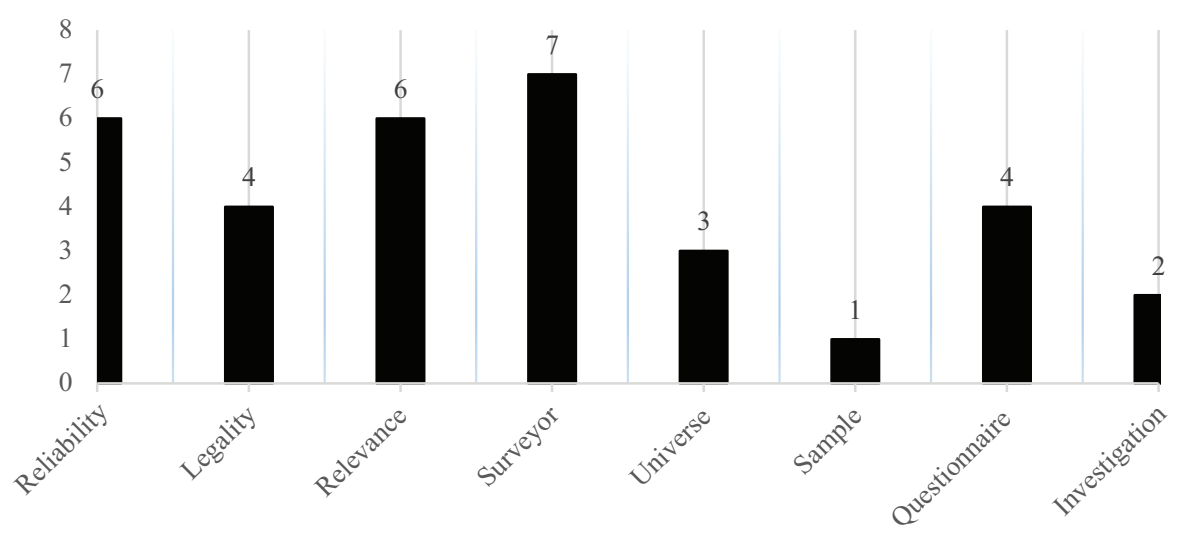

Figure 2 Main grounds to refuse survey evidence

Table 4 Admissibility and author of survey evidence

\begin{tabular}{llcc}
\hline & Admitted & Rejected & Total \\
\hline Plaintiff-submitted & $46(78 \%)$ & $13(22 \%)$ & $59(100 \%)$ \\
Defendant-submitted & $11(47.8 \%)$ & $12(52.2 \%)$ & $23(100 \%)$ \\
Court-commissioned & $11(100 \%)$ & $0(0 \%)$ & $11(100 \%)$ \\
Total & $68(75.3 \%)$ & $25(24.75 \%)$ & $93(100 \%)$ \\
\hline
\end{tabular}

Figure 2, the main refusal grounds often invoked by the courts in China include: (1) Reliability - the survey results are not reliable; (2) Legality - the survey cannot be regarded as a legal form of evidence; (3) Relevancy - the survey results are irrelevant to the case issue; (4) Surveyor - the survey has been prepared by one party or the survey agency not qualified to conduct an unbiased survey; (5) Universe - the definition of universe is improper; (6) Sample - the sampling method or sample size is inappropriate; (7) Questionnaire - the phrasing or format of questionnaire is problematic; (8) Investigation - the implementation of the investigation is defective. Unfortunately, in judicial opinions, China's courts rarely give any specific reasons why they favour or disfavour survey evidence tendered by litigants. Nor have the courts made available guidance to practitioners on how best to provide survey evidence. The courts' methodological criteria for examining the quality of a submitted survey in trademark cases remain unclear. This opacity may be partly due to a lack of guidelines and standards on the methodology of consumer surveys in China.

We developed our analysis through the estimation of three models, displayed in Table 4, Table 5 and Table 6. Each model tests the impact of different classification variables on the court's treatment of survey evidence.

Table 4 tests the relationship between whether the court credited survey evidence and which party submitted the survey. Our results show that the plaintiff-submitted surveys were more often admitted by the court than the defendant-submitted surveys. Out of 59 surveys submitted by the plaintiff, 46 surveys ( 78 per cent) were admitted as evidence and only 13 surveys ( 22 per cent) were completely rejected by the court. The data for defendants produces a different result (see Table 4). Out of 23 surveys submitted by the defendant, 11 surveys ( 47.8 per cent) were admitted as evidence 
Table 5 Admissibility and evidentiary purpose of survey evidence

\begin{tabular}{lrrc}
\hline & Admitted & Rejected & Total \\
\hline Confusion & $14(58.3 \%)$ & $10(41.7 \%)$ & $24(100 \%)$ \\
Reputation & $46(83.6 \%)$ & $9(16.4 \%)$ & $55(100 \%)$ \\
Both & $8(57.1 \%)$ & $6(42.9 \%)$ & $14(100 \%)$ \\
Total & 68 & 25 & 93 \\
\hline
\end{tabular}

Table 6 Admissibility and litigant's objection to survey evidence

\begin{tabular}{lccc}
\hline & Admitted & Rejected & Total \\
\hline Defendant-objected & $19(61.3 \%)$ & $12(38.7 \%)$ & $31(100 \%)$ \\
Defendant-accepted & $27(96.4 \%)$ & $1(3.6 \%)$ & $28(100 \%)$ \\
Total & 46 & 13 & 59 \\
& & & $16(100 \%)$ \\
Plaintiff-objected & $6(37.5 \%)$ & $10(62.5 \%)$ & $7(100 \%)$ \\
Plaintiff-accepted & $5(60.7 \%)$ & $2(39.3 \%)$ & 23 \\
Total & 11 & 12 & $1(100 \%)$ \\
& $1(100 \%)$ & $0(0 \%)$ & $10(100 \%)$ \\
Both-objected & $10(100 \%)$ & $0(0 \%)$ & 11 \\
Both-accepted & 11 & 0 & \\
Total & & & \\
\hline
\end{tabular}

and 12 surveys (52.2 per cent) were rejected by the court. Strikingly, all 11 surveys (100 per cent) which the court commissioned a survey company to produce were admitted without any exception. The data reflects that courts treat plaintiff-submitted surveys and defendant-submitted surveys differently. It seems that the courts are more likely to accept the plaintiff-submitted surveys, although it remains in doubt whether surveys produced by the plaintiff are actually more methodologically perfect than surveys prepared by the defendant.

Table 5 examines the relationship between whether the court credited the survey and the evidentiary purpose of a survey. The data in Table 5 show that the courts are more likely to admit surveys which were designed to prove the reputation of a disputed mark. Of 55 surveys which were used to prove trademark reputation, 46 surveys ( 83.6 per cent) were admitted by the courts, and only nine surveys ( 16.4 per cent) were rejected. Table 5 shows a relatively lower result for the trademark confusion survey. Of 24 surveys which were used to prove likelihood of confusion, 14 surveys (58.3 per cent) were admitted by the courts, and 10 surveys ( 41.7 per cent) were rejected. Of 14 surveys which had both evidentiary purposes, eight surveys (57.1 per cent) were admitted by the courts and six surveys (42.9 per cent) were rejected.

The data in Table 5 reflect that courts treat surveys with various evidentiary purposes differently. It might be useful for the litigants to prove the reputation of their mark in the minds of relevant consumers by submitting a survey. By contrast, it might be difficult for litigants to prove the likelihood of confusion by merely producing a consumer survey.

Table 6 investigates the relationship between whether the court credited the survey and whether the litigant raised an objection to surveys submitted by the other party. Our results indicate that the courts were more willing to accept the plaintiff's objection 
than the defendant's objection. Of 16 defendant-submitted surveys which were objected to by the plaintiffs, the court rejected 10 surveys ( 62.5 per cent) and only admitted six surveys (37.5 per cent). However, of 31 plaintiff-submitted surveys which were objected to by the defendants, the court admitted 19 surveys (61.3 per cent) and only rejected 12 surveys (38.7 per cent). Simply put, the objections raised by plaintiffs before the courts seem more effective than those of defendants.

Our results provide evidence that an unopposed survey may be more influential than one that is opposed. Of 28 plaintiff-submitted surveys which were accepted by the defendants, the court admitted 27 surveys (96.4 per cent), and only rejected one survey (3.6 per cent). Likewise, of seven defendant-submitted surveys which were accepted by the plaintiffs, the court admitted five surveys (60.7 per cent) and rejected only two surveys (39.3 per cent). Surprisingly, we notice that when litigants accepted the survey submitted by the opposing party as evidence, the courts were more likely to accept the plaintiff's survey than the defendant's. Once again, those results imply that courts treat plaintiff-submitted surveys and defendant-submitted surveys differently. Of 11 surveys commissioned by the court, the defendant raised an objection in only one survey. It should be noted that all those 11 surveys were admitted by the court, whether or not the litigants had any objection to the survey. It might be inferred that the survey evidence commissioned by the court is per se admissible.

\subsection{Finding 6: ability to help prove infringement}

Although consumer surveys are typically not used in trademark infringement cases, it remains to be seen whether surveys have any impact in supporting an allegation of trademark infringement. The association between the presentation of survey evidence and whether the court finally established trademark infringement is reported in this section. The outcome variable was defined and measured at two levels: 'Infringement' and 'Non-infringement'.

We begin our analysis with a simple count of wins and losses in our dataset. Coding whether a court favoured or disfavoured the plaintiff was relatively straightforward. The court found infringement in 69 out of 90 cases (a plaintiff win rate of 76.7 per cent) and failed to find infringement in 21 of 90 cases (a defendant win rate of 23.3 per cent). In short, plaintiffs win about two-thirds of the time in trademark infringement cases with the presence of survey evidence.

We developed our analysis through the estimation of three models, displayed in Tables 7, 8 and 9. Each model tests the impact of different variables on the court's finding of trademark infringement.

Table 7 examines the relationship between the probability of a court finding trademark infringement and whether the court admitted or rejected a survey as evidence. The introduction of survey evidence correlated with a higher chance of establishing trademark infringement and the impact is substantively impressive. Out of 66 cases

Table 7 Infringement and survey evidence

\begin{tabular}{lccc}
\hline & Infringement & Non-infringement & Total \\
\hline Admitted & $55(84.8 \%)$ & $11(15.2 \%)$ & $66(100 \%)$ \\
Rejected & $14(58.3 \%)$ & $10(41.7 \%)$ & $24(100 \%)$ \\
Total & $69(76.7 \%)$ & $21(23.3 \%)$ & $90(100 \%)$ \\
\hline
\end{tabular}


Table 8 Infringement and author of survey evidence

\begin{tabular}{lccr}
\hline & Infringement & Non-infringement & Total \\
\hline Plaintiff-submitted & $44(78.6 \%)$ & $12(21.4 \%)$ & $56(100 \%)$ \\
Defendant-submitted & $12(60 \%)$ & $8(40 \%)$ & $20(100 \%)$ \\
Both-submitted & $2(67 \%)$ & $1(33 \%)$ & $3(100 \%)$ \\
Court-commissioned & $11(100 \%)$ & $0(0 \%)$ & $11(100 \%)$ \\
Total & $69(76.7 \%)$ & $21(23.3 \%)$ & $90(100 \%)$ \\
\hline
\end{tabular}

Table 9 Infringement and admissibility of survey evidence

\begin{tabular}{llccc}
\hline & & Infringement & Non-infringement & Total \\
\hline Plaintiff-submitted & Admitted & $38(86.4 \%)$ & $6(13.6 \%)$ & $44(100 \%)$ \\
& Rejected & $6(50 \%) \downarrow$ & $6(50 \%)$ & $12(100 \%)$ \\
& Total & 44 & 12 & 56 \\
& & & & \\
Defendant-submitted & Admitted & $4(44.4 \%)$ & $5(55.6 \%)$ & $9(100 \%)$ \\
& Rejected & $8(72.7 \%)$ & $3(27.3 \%) \downarrow$ & $11(100 \%)$ \\
& Total & 12 & 8 & 20 \\
Both-submitted & Admitted & $2(100 \%)$ & $0(0 \%)$ & $2(100 \%)$ \\
& Rejected & $0(0 \%)$ & $1(100 \%)$ & $3(100 \%)$ \\
& Total & 2 & 1 & $11(100 \%)$ \\
Court-commissioned & Admitted & $11(100 \%)$ & $0(0 \%)$ & $0(100 \%)$ \\
& Rejected & $0(0 \%)$ & $0(0 \%)$ & 11 \\
\hline
\end{tabular}

in which survey evidence was presented and admitted, the court found infringement in 55 cases (a plaintiff win rate of 84.8 per cent), and found non-infringement only in 11 cases. These results are significantly higher than for the 'Rejected' category. Out of 24 cases when surveys were presented but not admitted into evidence, the court only found infringement in 14 cases (a plaintiff win rate of 58.3 per cent), and found non-infringement only in 10 cases.

Our results indicate that a credited survey increases the probability of a trademark infringement finding. On the other hand, inadmissible survey evidence with marginal quality markedly reduced the likelihood of establishing trademark infringement. These findings highlight the dramatic impact of presenting a survey that the court refuses to admit into evidence. Thus, it is of utmost importance for the litigants to ensure that a survey is properly developed according to widely acknowledged methodological criteria for conducting a consumer survey.

Table 8 introduces another set of classification variables by examining the correlation between the probability of a court finding of trademark infringement and the author of a survey. This model simply asks whether the plaintiff's or defendant's submission of a survey impacts on a court's likelihood of a trademark infringement finding. Our results reveal that a statistically significant relationship exists between litigants submitting a survey and a finding of trademark infringement. The impact of a survey differs according to which litigant submitted the survey. 
The plaintiff-submitted survey is significantly correlated with a finding of trademark infringement by the court. Of 56 cases in which the plaintiff presented surveys, the plaintiff won 44 cases (a plaintiff win rate of 78.6 per cent), and the defendant won 12 cases (21.4 per cent). This finding is not surprising. A consumer survey, representing powerful scientific evidence of likelihood of confusion or evidence of reputation of a disputed mark by presenting the opinions of relevant consumers, is supposed to help the plaintiffs establish trademark infringement.

Table 8 for defendants produces a different result. Defendants who presented survey evidence enjoyed a much lower likelihood of a finding of non-infringement. Our dataset included 20 cases where the defendant submitted survey evidence, in which the defendant only won 8 cases (a defendant win rate of 40 per cent), and the plaintiff won 12 cases (60 per cent). We also examine the correlation between court-commissioned surveys and trademark infringement outcomes. It should be noted that in all 11 cases in which the court commissioned the survey, the plaintiff won (a plaintiff win rate of 100 per cent). Of three cases in which both parties submitted surveys, the plaintiff won in two cases (67 per cent), and the defendant won one case (33 per cent).

Consistent with the findings in Tables 4 and 6, these results imply that courts treat plaintiff-submitted surveys and defendant-submitted surveys differently. Plaintiffs are far more likely to prevail in trademark cases with a submission of survey evidence than the defendants. Our results reveal that it is likely that plaintiff-submitted and courtcommissioned survey evidence increases significantly the probability of a trademark infringement finding. As Bird noted, a plaintiff-submitted survey may signal to the court that the plaintiff is serious about defending its trademark rights and is confident about winning its case. ${ }^{59}$

Table 9 investigates the impact of a credited survey on the case outcomes. The findings suggest that in the aggregate the odds of winning improve significantly with the admission of survey evidence by the court. These results correspond to the previous findings in Table 7 in that a credited survey increases the probability of a trademark infringement finding.

Our results reveal that it is likely that a plaintiff-submitted survey, when credited by the court, significantly increases the probably of a trademark infringement finding. Of the 12 opinions where the survey was rejected, only six were nevertheless able to obtain a finding of trademark infringement (a plaintiff win rate of 50 per cent). Of the 44 cases when the survey was submitted by the plaintiff and admitted by the court, the court ultimately found trademark infringement in 38 cases (a plaintiff win rate of 86.4 per cent). Overall, plaintiffs prevailed in 86.4 per cent of cases with survey evidence, as compared to winning only 50 per cent of the cases in which survey evidence was rejected. This represents an apparent 36.4 per cent increase in the probability of a trademark infringement finding. Our results report that a credited survey submitted by the defendant also has a statistically significant impact on the outcome of the dispute. Of the 11 opinions that did not credit the defendants' survey evidence, only three cases were found to be non-infringement (a defendant win rate of 27.3 per cent). Of the nine cases when the survey was submitted by the defendant and admitted by the court, the court ultimately found non-infringement in five cases (a defendant win rate of 55.6 per cent). The defendant prevailed in 55.6 per cent of cases with such evidence, as compared to winning only 27.3 per cent of the cases in which survey evidence was rejected. This represents an apparent 28.3 per cent increase in the probability of a non-trademark infringement finding.

59. Bird and Steckel, supra (n 45), at 1038. 


\subsection{Finding 7: non-survey evidence and survey evidence}

In this section, we introduce two sets of different but important variables: 'Name similarity' - the similarity of the litigants' marks; and 'Product similarity' - the proximity of litigants' goods in the marketplace. Our results find that these two factors are both influential on survey receptivity and the ultimate outcome of the dispute. More pertinent to the goal of this article, our results reveal that even when the influence of non-survey factors is separately taken into account, survey evidence indeed remains influential. The pattern of significance corresponds to previous findings.

\subsubsection{Name similarity and survey evidence}

Junior marks accused of infringing a senior trademark vary in terms of name similarity. In examining the likelihood of confusion, the court evaluates the degree of similarity of the trademarks involved. Table 10 measures the impact of name similarity on survey evidence receptivity and case outcome. For the purposes of analysis, we coded the 'Name Similarity' variable at two levels: 'Similar mark' - the disputed marks are similar; and 'Dissimilar mark' - the disputed marks are dissimilar.

As we expected, the results reported in Table 10 indicate that surveys were more likely to be admitted by the courts when the disputed marks were 'Similar' than when marks were 'Dissimilar'. Out of 76 cases where the disputed marks were similar, the court admitted survey evidence in 59 cases ( 77.6 per cent), and rejected in 17 cases (22.4 per cent). Out of 14 cases where the disputed marks were dissimilar, the court admitted survey evidence in seven cases (50 per cent), and rejected in seven cases (50 per cent). Likewise, the results reported in Table 10 indicate that trademark infringements were more likely to be established by the courts when the disputed marks were 'Similar' than when marks were 'Dissimilar'. Out of 76 cases in which the disputed marks were similar, the court found infringement in 68 cases (89.5 per cent), and found non-infringement in eight cases (10.5 per cent). Out of 14 cases in which the disputed marks were dissimilar, the court found infringement in only one case (7.1 per cent), and found non-infringement in 13 cases ( 92.9 per cent). The more similar the parties' trademarks, the higher the likelihood of establishing trademark infringement.

The results in Table 10 only serve as a face validity check of our study's findings. Table 11 examines the impact of survey evidence on case outcomes for different levels of name similarity of the litigants. Our results indicate that use of consumer surveys resulted in a statistically significant increase in the likelihood of finding trademark

Table 10 Impact of name similarity on survey evidence

\begin{tabular}{lccc}
\hline & Admitted & Rejected & Total \\
\hline Similar mark & $59(77.6 \%)$ & $17(22.4 \%)$ & $76(100 \%)$ \\
Dissimilar mark & $7(50 \%)$ & $7(50 \%)$ & $14(100 \%)$ \\
Total & 66 & 24 & 90 \\
\hline & Infringement & Non-infringement & Total \\
\hline Similar mark & $68(89.5 \%)$ & $8(10.5 \%)$ & $76(100 \%)$ \\
Dissimilar mark & $1(7.1 \%)$ & $13(92.9 \%)$ & $14(100 \%)$ \\
Total & 69 & 21 & 90 \\
\hline
\end{tabular}


Table 11 Impact of survey evidence on name similarity

\begin{tabular}{lllcr}
\hline & & Infringement & Non-infringement & Total \\
\hline Similar mark & Admitted & $54(91.5 \%)$ & $5(9.5 \%)$ & $59(100 \%)$ \\
& Rejected & $14(82.4 \%) \downarrow$ & $3(17.6 \%)$ & $17(100 \%)$ \\
& Total & 68 & 8 & 76 \\
Dissimilar mark & Admitted & $1(14.3 \%)$ & $6(85.7 \%)$ & $7(100 \%)$ \\
& Rejected & $0(0 \%) \downarrow$ & $7(100 \%)$ & $7(100 \%)$ \\
& Total & 1 & 13 & 14 \\
\hline
\end{tabular}

infringement by the court at each level of name similarity. Moreover, the impact of a survey varies depending on the degree of name similarity.

In the 'Similar mark' trademarks category, out of 17 cases in which surveys were presented and rejected by the court, trademark infringement was found in 14 cases (a plaintiff win rate of 82.4 per cent). Strikingly, out of 59 cases in which surveys were presented and admitted by the court, trademark infringement was found in 54 cases (a plaintiff win rate of 91.5 per cent). These incremental increases are significant and pragmatically important when considering strategy in litigation involving similar trademarks. In cases where the contesting parties have similar marks, the impact of an effective survey may be quite substantial.

The results are far more dramatic in the 'Dissimilar mark' category. The study's data indicate that survey evidence is more important in cases involving dissimilar trademarks. The magnitude of the impact is especially important to note. Out of seven cases in which surveys were presented and admitted by the court, trademark infringement was found only in one case (a plaintiff win rate of 14.3 per cent). Moreover, out of seven cases in which surveys were presented and rejected by the court, trademark infringement was not found in any cases (a plaintiff win rate of 0 per cent). In the 'Dissimilar mark' category, no plaintiff won the case after the court rejected the survey. Thus, the correlation between presenting surveys that are admitted into evidence and finding trademark infringement is very strong when the contesting parties used dissimilar trademarks. Surveys seem to be most helpful when the contesting marks are dissimilar. Without an admitted survey, it was very difficult to establish trademark infringement. However, it may not be easy for trademark litigants to conduct a survey that supports an allegation of trademark infringement by showing the likelihood of confusion when the disputed trademarks are dissimilar. Yet, the conclusions of our study suggest that these are certain situations where developing a consumer survey merits trademark litigants' serious consideration.

\subsubsection{Product similarity and survey evidence}

Trademark infringement cases brought against junior marks are used in connection with closely related or even unrelated goods or services. Table 12 measures the impact of product similarity on survey evidence receptivity and case outcome. For the purposes of analysis, we coded the 'Product similarity' variable at two levels: 'Similar product' - the disputed goods or service are similar; and 'Dissimilar product' - the disputed goods or service are dissimilar.

Strikingly, the results reported in Table 12 indicate that surveys were more likely to be admitted by the courts when the disputed products were 'Dissimilar' than when 
Table 12 Impact of product similarity on survey evidence

\begin{tabular}{llcc}
\hline & Admitted & Rejected & Total \\
\hline Similar product & $33(58.9 \%)$ & $23(41.1 \%)$ & $56(100 \%)$ \\
Dissimilar product & $33(97 \%) \uparrow$ & $1(3 \%)$ & $34(100 \%)$ \\
Total & 66 & 24 & 90 \\
\hline & Infringement & Non-infringement & Total \\
\hline Similar product & $40(71.4 \%)$ & $16(28.6 \%)$ & $56(100 \%)$ \\
Dissimilar product & $29(85.3 \%) \uparrow$ & $5(14.7 \%)$ & $34(100 \%)$ \\
Total & 69 & 21 & 90 \\
\hline
\end{tabular}

Table 13 Impact of survey evidence on product similarity

\begin{tabular}{llccc}
\hline & & Infringement & Non-infringement & Total \\
\hline Similar product & Admitted & $26(78.8 \%)$ & $7(21.2 \%)$ & $33(100 \%)$ \\
& Rejected & $14(60.9 \%)$ & $9(39.1 \%)$ & $23(100 \%)$ \\
& Total & 40 & 16 & 56 \\
Dissimilar product & Admitted & $29(87.9 \%)$ & $4(12.1 \%)$ & $33(100 \%)$ \\
& Rejected & $0(0 \%)$ & $1(100 \%)$ & $1(100 \%)$ \\
& Total & 29 & 5 & 34 \\
\hline
\end{tabular}

marks were 'Similar'. Out of 34 cases in which disputed products were dissimilar, the court admitted survey evidence in 33 cases (97 per cent), and rejected the surveys only in one case ( 3 per cent). Out of 56 cases in which disputed products were similar, the court admitted survey evidence in 33 cases (58.9 per cent), and rejected the surveys in 23 cases (41.1 per cent). Similarly, the results indicate that trademark infringements were more likely to be found by the courts when the disputed marks were 'Dissimilar' than when marks were 'Similar'. Out of 34 cases in which the disputed products were dissimilar, the court found infringement in 29 cases (85.3 per cent), and found non-infringement in only five cases (14.7 per cent). Out of 56 cases in which disputed products were similar, the court found infringement in 40 cases (71.4 per cent), and found non-infringement in 16 cases (28.6 per cent). The more dissimilar the parties' goods or service, the higher the likelihood of establishing trademark infringement.

The results in Table 12 only serve as a face validity check of our study's findings. Table 13 examines the impact of survey evidence on case outcomes for different levels of product similarity. The results indicate that surveys were correlated with greater success in finding trademark infringement, regardless of the proximity of the parties' goods or services.

In the 'Similar product' category, out of 23 cases in which surveys were presented and rejected by the court, trademark infringement was found in 14 cases (a plaintiff win rate of 60.9 per cent). Finally, in the 'Admitted' category, trademark infringement was found in 28 of 33 cases (a plaintiff win rate of 78.8 per cent). These increases are substantively impressive when considering strategy in litigation involving similar goods and services. In cases in which the parties have similar goods and services, the impact of an effective survey may be quite substantial. 
The influence of consumer surveys in cases in the 'Dissimilar product' category was even more pronounced. In the 'Admitted' category, out of 33 cases, trademark infringement was found in 29 cases (a plaintiff win rate of 87.9 per cent). However, in the 'Rejected' category, trademark infringement was found in no cases (a plaintiff win rate of 0 per cent). No court found trademark infringement in this category. It was extremely difficult to find trademark infringement without an admitted consumer survey in the 'Dissimilar Product' category.

In this section, we consider the impact of consumer surveys in the context of the strength of the litigants' non-survey evidence. In general, the weaker the similarity between the parties' trademarks and goods and services, the greater the value will be of presenting a survey. The results in Tables 11 and 13 indicate that survey evidence is of vital importance in cases involving dissimilar trademarks or products. In cases involving parties with dissimilar trademarks, plaintiffs prevailed in 0 per cent of the cases in which a survey was rejected, and 14.3 per cent in which the survey was admitted. Similarly, in cases involving dissimilar goods or services, plaintiffs prevailed in 0 per cent of the cases in which a survey was rejected, and 87.9 per cent in which the survey was admitted. The study's findings indicate that the weaker the similarity between the parties' trademarks and goods and services, the greater the value will be of presenting a survey.

Similarly, the results in Tables 11 and 13 indicate that in cases in which the parties had similar marks or similar goods or services, the incremental improvement in finding trademark infringement with admitted surveys was still meaningful. In cases in which the parties had similar trademarks, plaintiffs prevailed in 82.4 per cent of cases in which a survey was rejected and in 91.5 per cent of cases with admitted surveys. Likewise, in cases involving similar goods and services, plaintiffs prevailed in 60.9 per cent of cases in which a survey was rejected and in 78.8 per cent of cases with admitted surveys. These increases are statistically important when considering strategy in litigation involving even similar trademarks and closely related goods and services.

\section{DISCUSSION}

These findings reveal intriguing and useful information about the influence of survey evidence in China's courts and allow foreign enterprises to quantify the precise benefit of survey evidence in a variety of contexts. The discussion summarizes the key findings and implications for trademark litigants.

\subsection{The role of survey evidence in China's courts}

We uncovered the role of survey evidence in China's trademark infringement cases. As our findings show, the majority of litigants do not use consumer surveys in trademark infringement cases. A significant portion of trademark jurisprudence is developed without the aid of survey evidence. Presentation of survey evidence still remains an individual decision left to the trademark litigants. The reasons that many litigants are reluctant to present survey evidence include the monetary costs, time constraints, technical difficulties, the availability of other non-survey evidence, the value of the disputed mark at issue, predicted or obtained survey results, and other factors.

In trademark infringement cases the plaintiffs and the defendants may have different attitudes towards survey evidence. Comparatively speaking, due to the different 
burden of proof, the plaintiffs are more motivated to present survey evidence than the defendants. As to the evidentiary purpose of survey evidence, the plaintiffs would like to produce survey evidence to prove the reputation of senior marks, while the defendants would like to submit survey evidence to prove the non-existence of the likelihood of confusion between contested marks. Moreover, the plaintiffs are more critical about the validity of survey evidence presented by the defendants at the cross-examination stage.

The admission rate of survey evidence in trademark infringement cases is exceptionally high in China. Out of 93 surveys, the courts have accepted more than three-quarters of the surveys as admissible evidence, which is far beyond the admission rate in other jurisdictions. Unfortunately, China's courts hardly gave any specific reasons about why they favour or disfavour the survey evidence, and how they determine the weight of survey evidence in judicial opinions. Nor have the courts made guidance available to practitioners on how best to provide survey evidence. The court's methodological criteria of examining the quality of a submitted survey in trademark cases remains blank and unclear.

The courts should evaluate the admissibility and weight of survey evidence according to well-established criteria. In theory, courts should treat survey evidence submitted by either party equally, but our data proves otherwise. The study's findings repeatedly indicate that survey evidence may be susceptible to litigant-status preferences. Specifically speaking, courts in China treat plaintiff-submitted surveys more favourably than defendant-submitted surveys. Although the burdens of proof are different between the plaintiffs and the defendants, the evidentiary weight of a survey should not vary significantly simply due to which party submitted it.

While the presentation of survey evidence is not mandatory to establish trademark infringement, such solid evidence may have persuasive power under certain circumstances. The study's findings repeatedly indicate that the quality of surveys presented is strongly and statistically associated with case outcomes. Survey evidence may play varying roles for litigants in trademark cases. The study identified circumstances in which the presentation of such evidence is likely to have a greater impact on outcomes, and when the impact of surveys is minimal or even negative. Many surveys suffer from multiple methodological problems. A poorly conducted survey can give misleading results and markedly reduced its impact on case outcomes. The future of consumer surveys in trademark litigation is likely to depend on the quality of survey design. Thus, it is of utmost importance for trademark litigants to ensure that a survey is properly developed according to scientific and methodical criteria.

\subsection{Limitations and further research}

We only examined a 16-year period of court practice in China. It is unclear whether our results are stable over time. Three caveats from our dataset bear mentioning. First, the data only include cases that actually went to court, and we do not know the role that surveys played in the pre-trial stage. Consumer surveys may play a central role in the progress of trademark litigation before cases appear in court. Second, although we believe that PkuLaw represents a comprehensive review of the cases during the study period, the electronic databases do not report every judicial opinion in China. Third, the limitation of the size of the defendant-submitted surveys and court-rejected surveys dataset is also a restriction. As such, our conclusions regarding those surveys can only be tentative owing to small samples. The courts frequently 
raised legitimate concerns over the validity and reliability of survey evidence introduced by the litigants. Future studies should provide important research on examining under what conditions surveys are most persuasive to a court, or surveys are most vulnerable to judicial critique.

\section{CONCLUSION}

A consumer survey, if properly conducted, can be a potent legal tool in trademark cases. The value of surveys depends on providing standards for survey design and educating judges to evaluate a survey. Due to the infrequent use of survey evidence, there are few instances wherein China's courts rule on the criteria in examining survey evidence. The trademark law has not yet developed a general rule for the treatment of survey evidence. However, the courts should state clearly their requirements for acceptable survey evidence. In order to judge the quality of a survey fairly, the establishment of a standardized methodology for litigants is of vital importance. Suggested guidelines should include every aspect of a consumer survey, such as universe definition, sample selection and sample size, questionnaire wording and format, expertise of the interviewers, implementation of an investigation, data collection and survey report. These guidelines should help to indicate the method of producing a survey and standard in judging the weight of survey evidence. 